



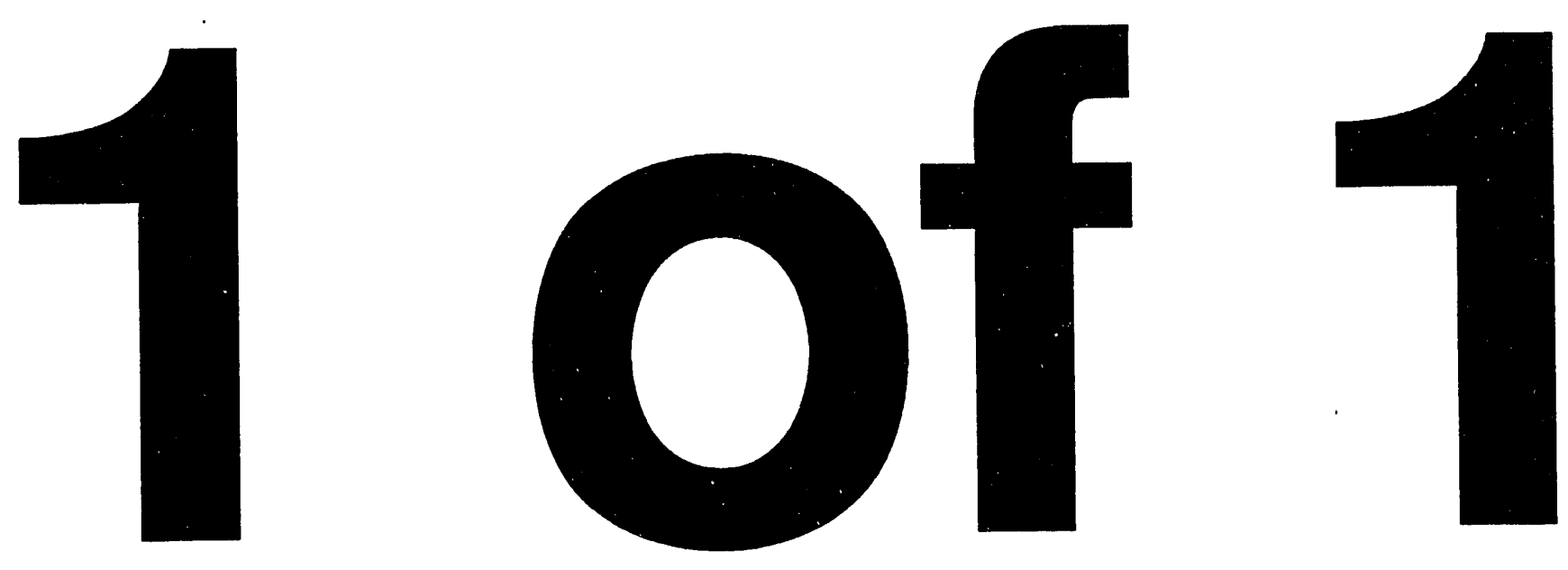


\section{THERMAL ANALYSIS OF THE HORIZONTAL SHIPPING CONTAINER FOR NORMAL CONDITIONS OF TRANSPORT WITH SOLAR INSOLATION}

Ed Stumpfl

Y-12 Packaging Department Defense Programs Engineering Services

April 2, 1993 


\section{DISCLAIMER}

This report was prepared as an account of work sponsored by an agency of the United States Government. Neither the United States Government nor any agency thereof, nor any of their employees, makes any warranty, express or implied, or assumes any legal liability or responsibility for the accuracy, completeness, or usefulness of any information, apparatus, product, or process disclosed, or represents that its use would nut infringe privately owned rights. Reference herein to any specific commercial product, process, or service by trade name, trademark, manufacturer, or otherwise, does not necessarily constitute or imply its endorsement, recommendation, or favoring by the Uniteu States Government or any agency thereof. The views and opinions of authors expressed herein do not necessarily state or reflect those of the United States Government or any agency thereof. 


\title{
THERMAL ANALYSIS OF THE HORIZONTAL SHIPPING CONTAINER FOR NORMAL CONDITIONS OF TRANSPORT WITH SOLAR INSOLATION
}

\author{
M.R. Feldman and J.C. Anderson
}

A thermal analysis of the horizontal shipping container (HSC) was performed to determine the temperatures at the outer surface of the inner container during normal conditions of transport with incident solar radiation. There are two methods by which this analysis can be performed: (1) it can be run as a steady-state problem where it is assumed that the incident solar radiation is applied to the package 24 hours per day, or (2) it can be run as a cyclic transient problem where the incident solar radiation is applied for 12 hours per day and the other 12 hours there is assumed to be no incident solar radiation. The steady-state method was initially attempted, but the temperatures determined from this analysis were judged to be significantly higher than one would find in the cyclic case. Thus, it was deemed necessary to perform a transient analysis to determine a more realistic temperature distribution within the HSC during normal conditions of transport.

The heat transfer code HEATING $7.1^{1}$ was used to perform these calculations. HEATING 7.1 is a heat conduction code capable of handling radiation, convection (forced and natural), and heat flux boundary conditions. Heat generation within a material is also possible with HEATING 7.1 but was not used in any of the models presented here. The models used here are one-dimensional in the radial direction. Three different cases were examined. Initially, two cases (case 1 and case 2) which included a thermal mass within the inner container were examined; one of them assumed that a 0.5 -in. air gap existed between the two layers of Celotex ${ }^{\mathrm{TM}}$, and the other assumed that the air gap did not exist. In reality, the HSC was manufactured with a 0.25 -in. gap between concentric rings of Celotex ${ }^{\mathrm{TM}}$. Thus, when the container is loaded and is in its normal condition of transport (horizontal), there is a 0.50 -in. gap between Celotex $^{\mathrm{TM}}$ rings at the top of the package and no gap at the bottom (this is shown clearly in Fig. 1). The first model was run with the air gap, since it was assumed that the upper portion of the container would receive the most incident solar radiation. Heat transfer across the gap is assumed to occur solely by radiant exchange. Then, to be conservative, the same boundary conditions were applied to a model which did not contain an air gap, which is equivalent to saying that 12 hours of direct sunlight were somehow able to shine on the bottom of the HSC. Thus, modeling of the container without an air gap represents a slight conservancy in the second model.

For case 3, there was assumed to be no gap and the thermal mass contained inside the inner container was replaced with an inert gas (see Table 1 for summary of cases). For some portions of the HSC this is the case, particularly in the area near the inner container seal. Because the inert gas was assumed in this model, slightly higher temperatures were found at the outside of the inner container. Thus, case 3 is the most conservative of the three models and results in the highest temperature at the outside of the inner container (see Table 1). Therefore, case 3 is the one that will be fully described and discussed here. Figure 1 is a two-dimensional representation of the area modeled. The air gap model is depicted by starting at the uppermost point (node 74) on the figure and following the radial line down to the center of the figure (node 1). The model without the air gap is depicted by starting at the bottom of the figure (node 73) and following the radial line up to the center of the figure (node 1). It is evident from Fig. 1 that the gap between Celotex ${ }^{\mathrm{TM}}$ layers does exist in the upper portion of the container during normal conditions of transport; thus, not having the gap in a model represents a conservative approach. 




Note : All dimensions are in inches.

Fig. 1 Simplified HSC radial schematic showing material placement for models with and without gap between Celotex ${ }^{\mathrm{TM}}$ layers. 
Table 1. Maximum Inner Container Temperatures for Normal Conditions of Transport with Solar Insolation for Horizontal Shipping Container

\begin{tabular}{|c|l|c|}
\hline CASE & \multicolumn{1}{|c|}{ DESCRIPTION } & $\begin{array}{c}\text { MAX TEMP } \\
\left({ }^{\circ} \mathrm{F}\right)\end{array}$ \\
\hline 1 & $\begin{array}{l}\text { Thermal mass in inner container with gap between Celotex } \\
\text { layers. }\end{array}$ & $141.86 \dagger$ \\
\hline 2 & $\begin{array}{l}\text { Thermal mass in inner container without gap between Celotex } \\
\text { layers. }\end{array}$ & $142.25 \ddagger$ \\
\hline 3 & Inert gas in inner container without gap between Celotex layers. & 142.78 \\
\hline $\begin{array}{l}\text { If After } 50 \text { day transient, temperature was still rising } 0.04^{\circ} \mathrm{F} / \text { day } \\
\text { After } 75 \text { day transient, temperature was still rising } 0.01^{\circ} \mathrm{F} / \text { day }\end{array}$ \\
\hline
\end{tabular}

Each of the models analyzed incorporates three different materials for which material properties must be defined. There is a total of four different materials due to the fact that some models have a thermal mass within the inner container and some have an inert gas. The other two materials which are modeled are stainless steel 304 (inner and outer containers) and Celotex ${ }^{\mathrm{TM}}$ (between the inner and outer containers). Property data for all four of these materials can be found in Table 2. Where property data varied significantly with temperature, temperature dependent properties were used.

For these models, incident solar radiation is imparted to the HSC through the use of a heat flux boundary condition applied to the outer surface of the outer container. This condition is applied for 12 hours per day and not applied for the other 12 hours per day. The outer surface of the outer container, which represents the outermost edge of the model, is assumed to have a emissivity value of $0.56 .^{2}$ The heat flux boundary condition is not affected by this emissivity value, but the value does control the rate at which the models transfer heat to their surroundings. All surroundings are assumed to be at a constant temperature of $100^{\circ} \mathrm{F}, 24$ hours per day throughout the transient analysis. Due to the fact that the surface area represented by the package's surroundings are infinite, the emissivity of these surroundings is not significant (i.e., can be assumed to be 1.0). Thus, the overall gray-body interchange factor between the package and its surroundings is $0.56 \sigma$ where $\sigma$ is the Stefan-Boltzmann constant. Heat is also transferred to the container's surroundings by natural convection. The natural convection heat transfer coefficient is calculated by the equation: ${ }^{3}$

$$
\mathrm{htc}=0.18(\Delta \mathrm{T})^{0.33}
$$

where

$$
\begin{aligned}
& \text { htc }=\text { the heat transfer coefficient in } \mathrm{Btu} /\left(\mathrm{hr}-\mathrm{ft}^{2}-{ }^{\circ} \mathrm{F}\right), \\
& \Delta \mathrm{T}=\text { the difference in temperature between the outer surface of the package and its surroundings. }
\end{aligned}
$$

Heat is then transferred through the model by conduction (for models with a gap, heat transfer across the gap is modeled as radiation only, emissivity $=1.0$ ). 
Table 2. Property Data for Thermal Analysis of HSC for Normal Conditions of Transport with Solar Insolation ${ }^{2}$

\begin{tabular}{|c|c|c|c|c|c|c|}
\hline \multirow[t]{2}{*}{ MATERIALS } & \multicolumn{2}{|c|}{$\begin{array}{l}\text { THERMAL } \\
\text { CONDUCTIVITY }\end{array}$} & \multicolumn{2}{|c|}{ DENSITY } & \multicolumn{2}{|c|}{ SPECIFIC HEAT } \\
\hline & $\begin{array}{c}\text { Temp. } \\
\left({ }^{\circ} \mathrm{F}\right)\end{array}$ & $\mathrm{Btu} /\left(\mathrm{hr}-\mathrm{ft}-{ }^{\circ} \mathrm{F}\right)$ & $\begin{array}{c}\text { Temp. } \\
\left({ }^{\circ} \mathrm{F}\right)\end{array}$ & $\mathrm{lbs} / \mathrm{ft}^{3}$ & $\begin{array}{c}\text { Temp. } \\
\left({ }^{\circ} \mathrm{F}\right)\end{array}$ & $\mathrm{Btu} /\left(\mathrm{lb}-{ }^{\circ} \mathrm{F}\right)$ \\
\hline Stainless Steel 304 & $\begin{array}{r}32.0 \\
212.0 \\
932.0 \\
1292.0\end{array}$ & $\begin{array}{l}7.7411 \\
9.4344 \\
12.579 \\
14.998 \\
\end{array}$ & All & 494.43 & $\begin{array}{l}32.0 \\
752.0\end{array}$ & $\begin{array}{l}0.12 \\
0.135\end{array}$ \\
\hline Celotex $^{\mathrm{TM}}$ & $\begin{array}{r}77.0 \\
186.8 \\
294.8 \\
438.8 \\
532.4\end{array}$ & $\begin{array}{l}3.0624 \mathrm{E}-02 \\
3.4091 \mathrm{E}-02 \\
3.6403 \mathrm{E}-02 \\
3.7558 \mathrm{E}-02 \\
2.9469 \mathrm{E}-02\end{array}$ & $\begin{array}{l}77.0 \\
294.8 \\
438.8 \\
532.4\end{array}$ & $\begin{array}{l}16.856 \\
17.854 \\
18.541 \\
19.540\end{array}$ & $\begin{array}{l}77.0 \\
186.8 \\
294.8\end{array}$ & $\begin{array}{l}0.30574 \\
0.35972 \\
0.41681\end{array}$ \\
\hline Thermal Mass & All & 32.544 & All & 230.40 & All & 0.1503 \\
\hline Inert Gas & $\begin{array}{r}32.0 \\
212.0 \\
572.0\end{array}$ & $\begin{array}{l}0.0095795 \\
0.0123373 \\
0.0170546\end{array}$ & All & 0.113715 & All & 0.124 \\
\hline
\end{tabular}

To conserve money, time, and computer resources, all models for normal conditions of transport with incident solar radiation were one-dimensional in the radial direction. The use of one-dimensional models to mimic an actual two-dimensional case of thin-shelled Celotex ${ }^{\mathrm{TM}}$-based shipping containers has previously been explored. ${ }^{2}$ It was found that edge effects were negligible and that temperatures varied by less than $0.1^{\circ} \mathrm{C}$ for several different cases. Although the conditions used in the above reference are not precisely the same as here, there is no doubt that the one-dimensional models used here are conservative. That is, the model used here assumes an infinitely long cylinder the entire surface of which is subject to daily heat loads of $126.84 \mathrm{Btu} / \mathrm{h}-\mathrm{ft}^{2}\left(400 \mathrm{~W} / \mathrm{m}^{2}\right)$ for 12 hours over the entire shell of the container. A two-dimensional model would not have been infinitely long, but would have had an incident solar radiation heat load of $63.42 \mathrm{Btu} / \mathrm{h}-\mathrm{ft}^{2}\left(200 \mathrm{~W} / \mathrm{m}^{2}\right)$ for 12 hours per day placed on the ends of the model. With this thermal load being significantly smaller on the ends, it is clear that the assumption of a one-dimensional infinite cylinder is conservative. It should be noted that in the study referenced above, the same boundary conditions were applied to all surfaces of the shipping container (the side and ends). ${ }^{4}$ Thus, in that case, reduction to one-dimensional modeling is a valid assumption but is not necessarily conservative. Because the heat loads required on the ends of the HSC for normal conditions of transport with insolation are only half that required on the sides, the one-dimensional assumption, in this case, is conservative. It should also be noted that the heat load applied as incident solar radiation is that specified by IAEA regulations and is about $3.6 \%$ greater than that required by 10 CFR 71 .

Figure 2 shows the temperature history for case 3 of the HSC container during normal conditions of transport with an incident solar load of $400 \mathrm{~W} / \mathrm{m}^{2}$. Temperatures both at the outside of the outer 
container and at the outside of the inner container are plotted as a function of time in Fig. 2. Data shown on this figure are taken only every 12 hours, and the graphics program then connects the data points. Therefore, the maximum temperature oscillations at the outer surface are shown, but the straight lines drawn between data points are misleading. This figure shows data for a 50-day period in which the ambient temperature was constant at $100^{\circ} \mathrm{F}$ for the entire period. Insolation is applied and then not applied to the container for alternating 12 -hour periods. After a period of about 33 days, the temperature at the inner container reached its maximum temperature of $142.8^{\circ} \mathrm{F}$. The model was allowed to run past this point to assure that a quasi-steady-state temperature distribution had been reached inside the container. This is termed "quasi-steady-state" due to the fact that it is not true steady-state, as the temperature varies through the course of a day. However, it is steady in that from one day to the next the temperatures are the same (i.e. the temperature at 8:00 a.m. on day 49 is the same as the temperature at 8:00 a.m. on day 50). The only data shown in Fig. 2 are from two nodal points because in this study they represent the data that are most significant. The outer container temperatures show that the insolation boundary condition has been correctly applied, and the temperature at the outermost point of the inner container represents a conservative estimate of the temperature at the inner container seal and the temperature of the contents of the inner container.

Figure 3 shows the final temperature distribution throughout the container, for case 3 , both with and without insolation. It is apparent from this figure that although the outer container temperature varies through the day (as the sun rises and sets) temperatures at the inner container are constant for all practical purposes. Additionally, Fig. 4 shows the flurtuation on the outer container outer surface over a 24-hour period after quasi-steady-state has been reached for case 3. This representation of the temperatures on the outside of the outer container is a much better representation than that shown in Fig. 2. Finally, Fig. 5 shows the fluctuation in temperature for case 3 at the outside of the inner container during a 24-hour period (the same period shown in Figure 4). This temperature fluctuates less than $2^{\circ} \mathrm{F}$ during the period and returns to the same initial value at the end of the period indicating that inner container temperatures have reached a maximum.

HEATING 7.1 input data for case 3 have been included as an appendix to this report. 


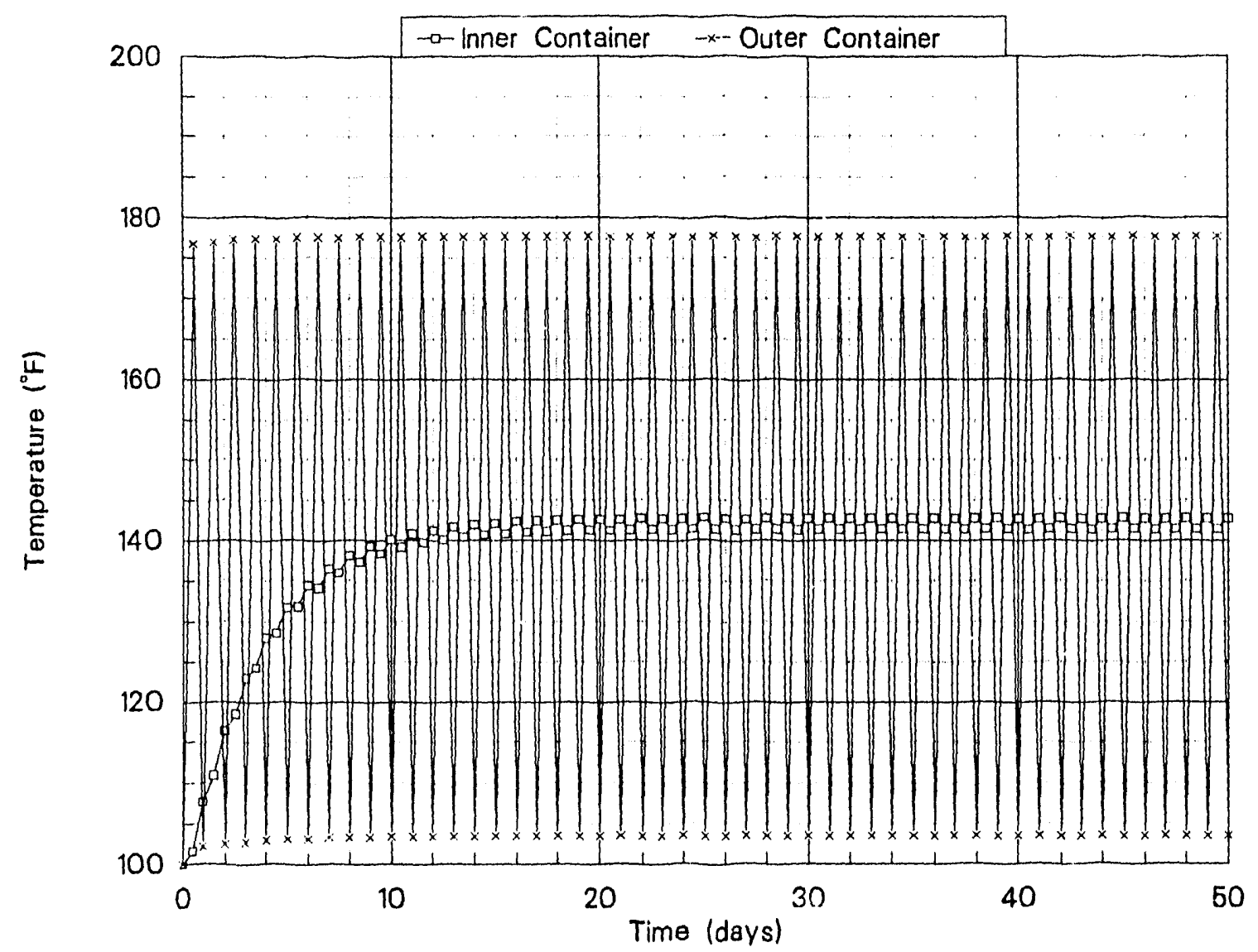

Fig. 2 Temperature vs time for HSC outer and inner containers during normal conditions of transport w/insolation for $\mathbf{5 0}$ day transient for case 3. 







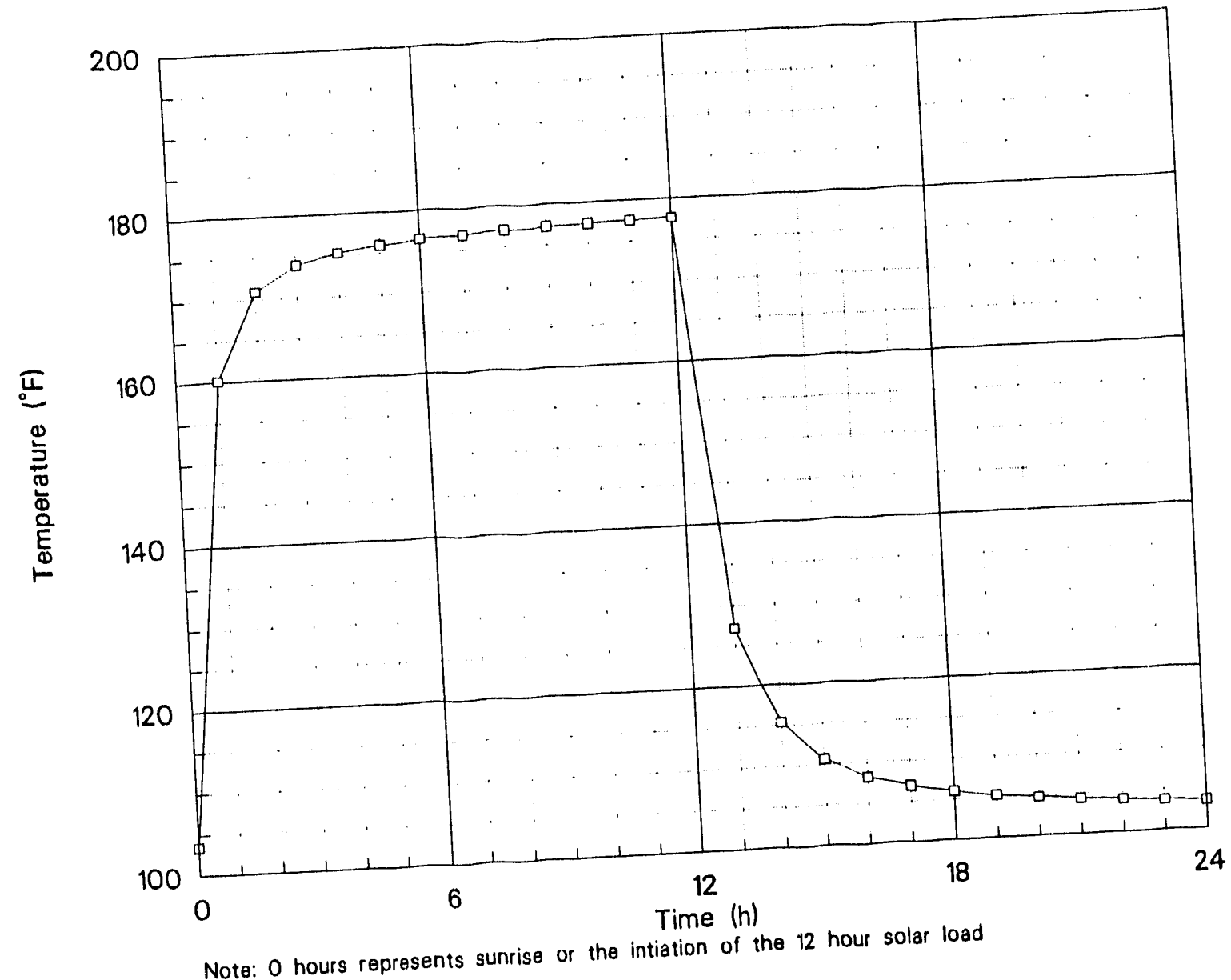

Fig. 4 Temperature vs time for HSC outer container during normal conditions of transport w/insolation for $5^{\text {st }}$ day of transient for case 3 . 


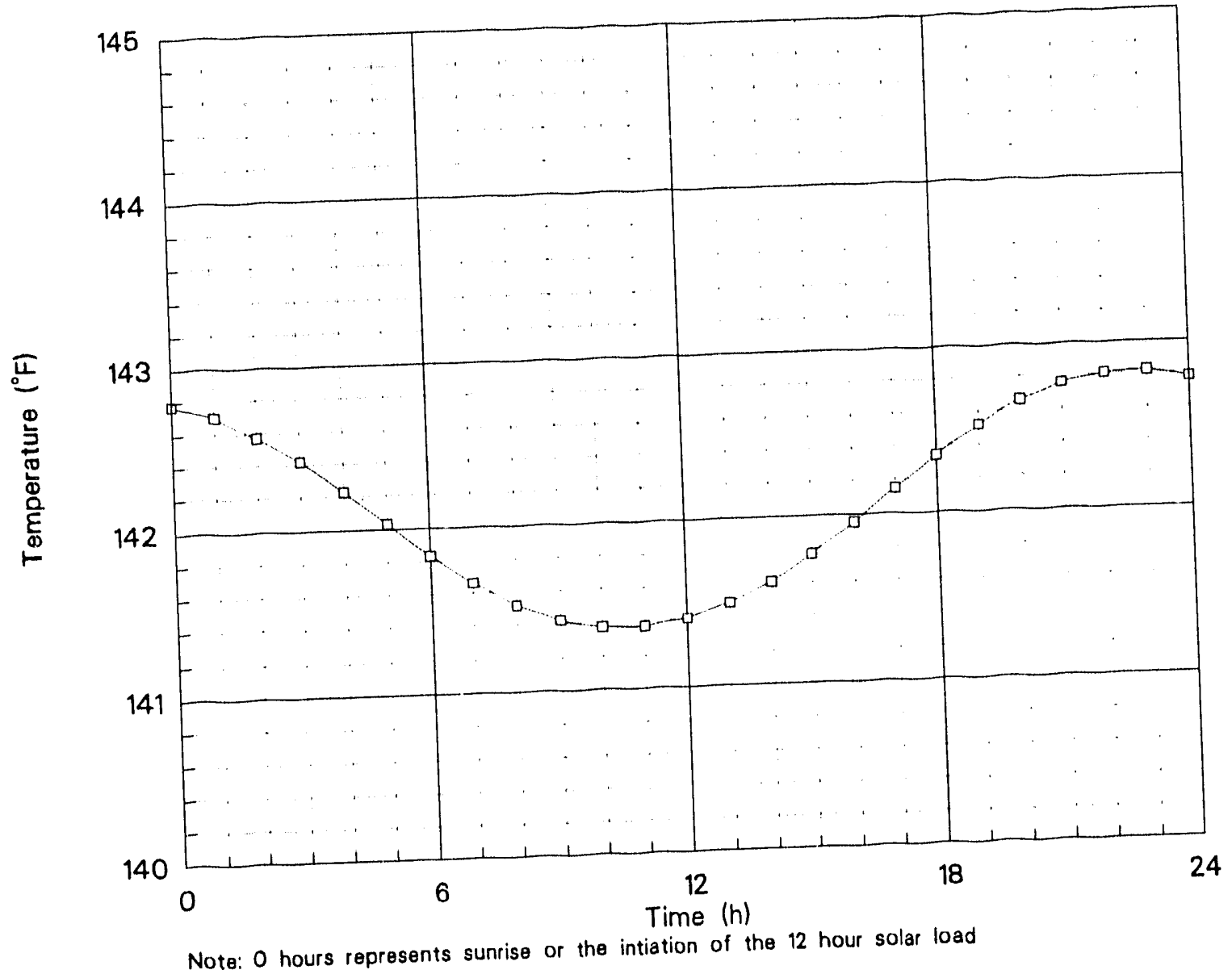

Fig. 5 Temperature vs time for HSC inner container during normal conditions of transport w/insolation for $51^{\text {st }}$ day of transient for case 3 . 


\section{REFERENCES}

1. K. W. Childs, HEATING ZI User's Manual, K/CSD/TM-96, Oak Ridge, TN, 1991.

2. Personal Communication with Tom Wright, Weapons Support Group, Mechanical Design Division, Y-12 Plant, Oak Ridge, TN, January, 1993.

3. F. Kreith, Principles of Heat Transfer, Scranton, PA, 1967. 


\section{APPENDIX A}

\section{HEATING 7.1 INPUT DECK FOR CASE 3}

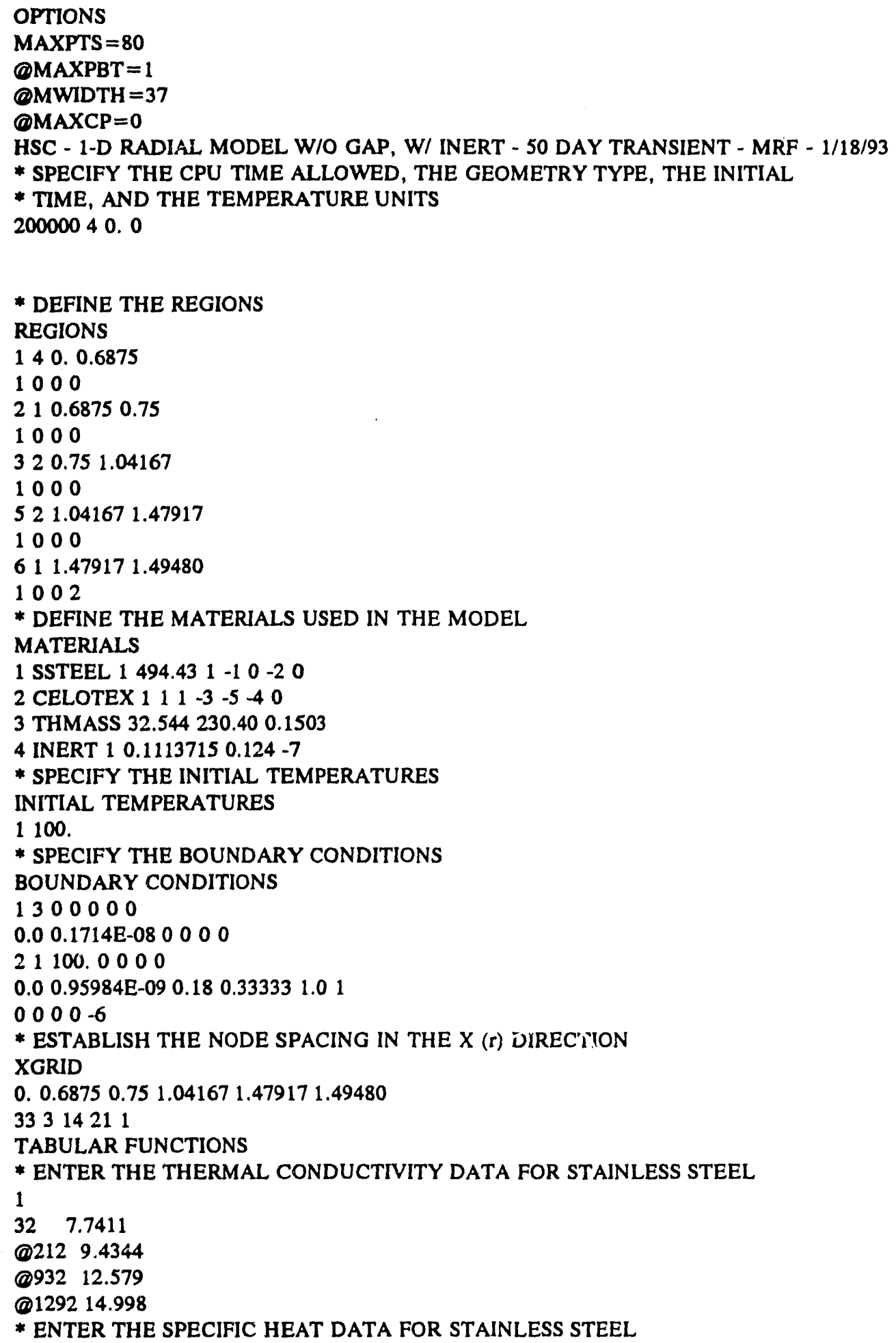

* ENTER THE SPECIFIC HEAT DATA FOR STAINLESS STEEL 


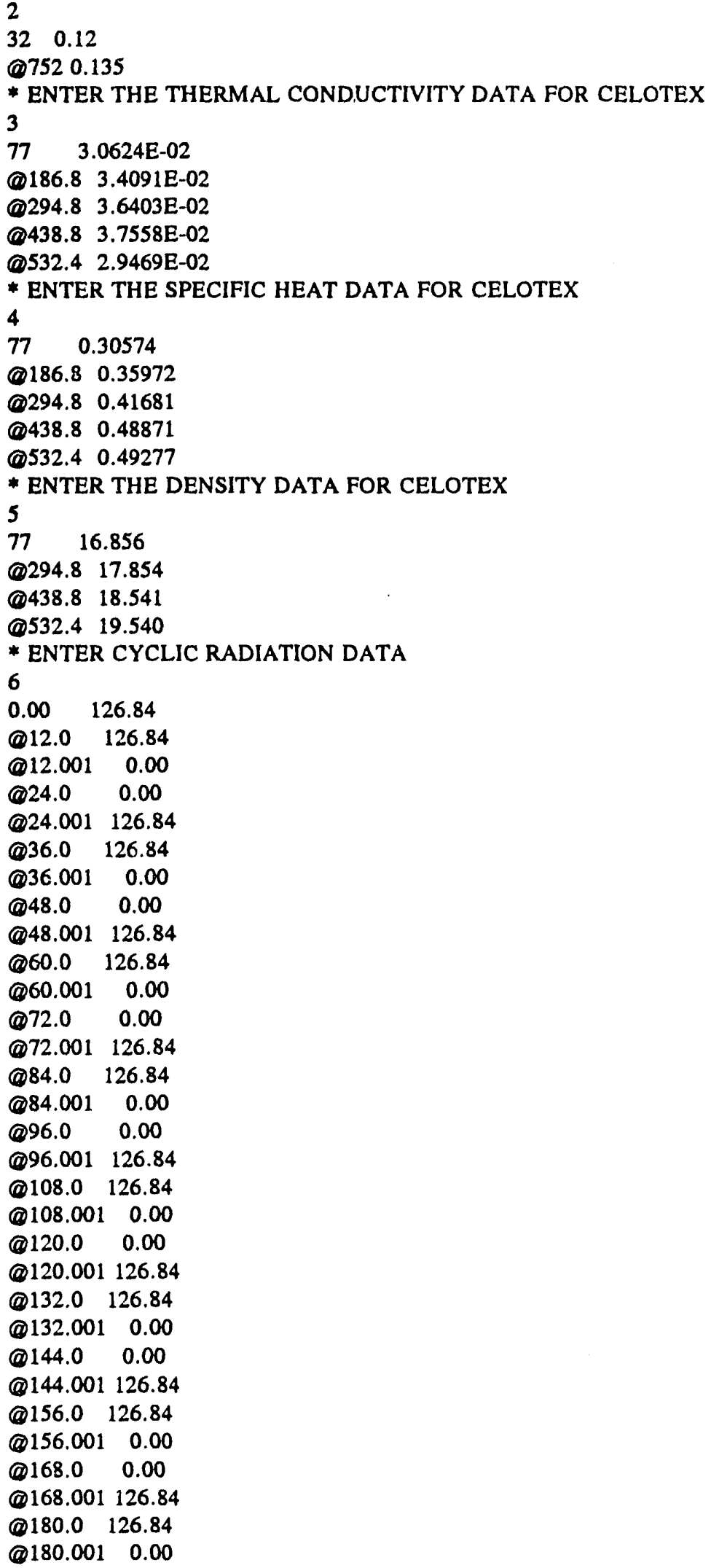




\begin{tabular}{|c|c|}
\hline \multicolumn{2}{|c|}{$@ 192.0 \quad 0.00$} \\
\hline \multicolumn{2}{|c|}{$@ 192.001126 .84$} \\
\hline \multicolumn{2}{|c|}{$@ 204.0126 .84$} \\
\hline$@ 204.001$ & 0.00 \\
\hline$@ 216.0$ & 0.00 \\
\hline \multicolumn{2}{|c|}{$@ 216.001126 .84$} \\
\hline \multicolumn{2}{|c|}{$@ 228.0 \quad 126.84$} \\
\hline$@ 228.001$ & 0.00 \\
\hline$@ 240.0$ & 0.00 \\
\hline \multicolumn{2}{|c|}{$\$ 240.001126 .84$} \\
\hline \multicolumn{2}{|c|}{$@ 252.0126 .84$} \\
\hline$@ 252.001$ & 0.00 \\
\hline$@ 264.0$ & 0.00 \\
\hline$@ 264.001$ & 126.84 \\
\hline$@ 276.0 \quad 1$ & 126.84 \\
\hline$@ 276.001$ & 0.00 \\
\hline$@ 288.0$ & 0.00 \\
\hline$@ 288.001$ & 126.84 \\
\hline$@ 300.01$ & 126.84 \\
\hline$@ 300.001$ & 0.00 \\
\hline$@ 312.0$ & 0.00 \\
\hline (\$312.001 & 126.84 \\
\hline Q 324.0 & 126.84 \\
\hline$@ 324.001$ & 0.00 \\
\hline$@ 336.0$ & 0.00 \\
\hline$@ 336.001$ & 126.84 \\
\hline$@ 348.0$ & 126.84 \\
\hline$@ 348.001$ & 0.00 \\
\hline$@ 360.0$ & 0.00 \\
\hline$@ 360.001$ & 126.84 \\
\hline$@ 372.0$ & 126.84 \\
\hline$@ 372.001$ & 0.00 \\
\hline$@ 384.0$ & 0.00 \\
\hline$@ 384.001$ & 1126.84 \\
\hline$@ 396.0$ & 126.84 \\
\hline$@ 396.001$ & 10.00 \\
\hline$@ 408.0$ & 0.00 \\
\hline$@ 408.001$ & 1126.84 \\
\hline$@ 420.0$ & 126.84 \\
\hline (1) 420.001 & 10.00 \\
\hline @. 32.0 & 0.00 \\
\hline$@ 432.001$ & 1126.84 \\
\hline$@ 444.0$ & 126.84 \\
\hline$@ 444.001$ & 10.00 \\
\hline$@ 456.0$ & 0.00 \\
\hline$@ 456.001$ & 11126.84 \\
\hline$@ 468.0$ & 126.84 \\
\hline$@ 468.001$ & 0.00 \\
\hline$@ 480.0$ & 0.00 \\
\hline$@ 480.001$ & 1126.84 \\
\hline @492.0 & 126.84 \\
\hline$@ 492.001$ & 10.00 \\
\hline$@ 504.0$ & 0.00 \\
\hline$@ 504.001$ & 126.84 \\
\hline$@ 516.0$ & 126.84 \\
\hline$@ 516.001$ & $01 \quad 0.00$ \\
\hline
\end{tabular}




\begin{tabular}{|c|c|}
\hline @528.0 & 0.00 \\
\hline$@ 528.0011$ & 126.84 \\
\hline$@ 540.0 \quad 12$ & 126.84 \\
\hline$@ 540.001$ & 0.00 \\
\hline$@ 552.0$ & 0.00 \\
\hline (1552.001 1 & 126.84 \\
\hline$@ 564.0 \quad 1$ & 126.84 \\
\hline$@ 564.001$ & 0.00 \\
\hline$@ 576.0$ & 0.00 \\
\hline$@ 576.001$ & 126.84 \\
\hline$@ 588.0$ & 126.84 \\
\hline$@ 588.001$ & 0.00 \\
\hline$@ 600.0$ & 0.00 \\
\hline$@ 600.001$ & 126.84 \\
\hline$@ 612.0 \quad 1$ & 126.84 \\
\hline$@ 612.001$ & 0.00 \\
\hline @624.0 & 0.00 \\
\hline$@ 624.001$ & 126.84 \\
\hline$@ 636.0$ & 126.84 \\
\hline$@ 636.001$ & 0.00 \\
\hline$@ 648.0$ & 0.00 \\
\hline$@ 648.001$ & 126.84 \\
\hline$@ 660.0$ & 126.84 \\
\hline$@ 660.001$ & 0.00 \\
\hline @672.0 & 0.00 \\
\hline$@ 672.001$ & 126.84 \\
\hline$@ 684.0$ & 126.84 \\
\hline$@ 684.001$ & 0.00 \\
\hline$@ 696.0$ & 0.00 \\
\hline$\$ 696.001$ & 126.84 \\
\hline$@ 708.0$ & 126.84 \\
\hline$@ 708.001$ & 0.00 \\
\hline$@ 720.0$ & 0.00 \\
\hline$@ 720.001$ & 1126.84 \\
\hline$@ 732.0$ & 126.84 \\
\hline$@ 732.001$ & 10.00 \\
\hline$@ 744.0$ & 0.00 \\
\hline$@ 744.001$ & 1126.84 \\
\hline$@ 756.0$ & 126.84 \\
\hline$@ 756.001$ & 10.00 \\
\hline$@ 768.0$ & 0.00 \\
\hline @768.001 & 1126.84 \\
\hline$@ 780.0$ & 126.84 \\
\hline$@ 780.001$ & 10.00 \\
\hline$@ 792.0$ & 0.00 \\
\hline$@ 792.001$ & 1126.84 \\
\hline$@ 804.0$ & 126.84 \\
\hline$@ 804.001$ & $1 \quad 0.00$ \\
\hline$@ 816.0$ & 0.00 \\
\hline$@ 816.001$ & $1 \quad 126.84$ \\
\hline$@ 828.0$ & 126.84 \\
\hline$@ 828.001$ & 10.00 \\
\hline$@ 840.0$ & 0.00 \\
\hline$@ 840.00$ & 1126.84 \\
\hline$@ 852.0$ & 126.84 \\
\hline$@ 852.00$ & $01 \quad 0.00$ \\
\hline
\end{tabular}




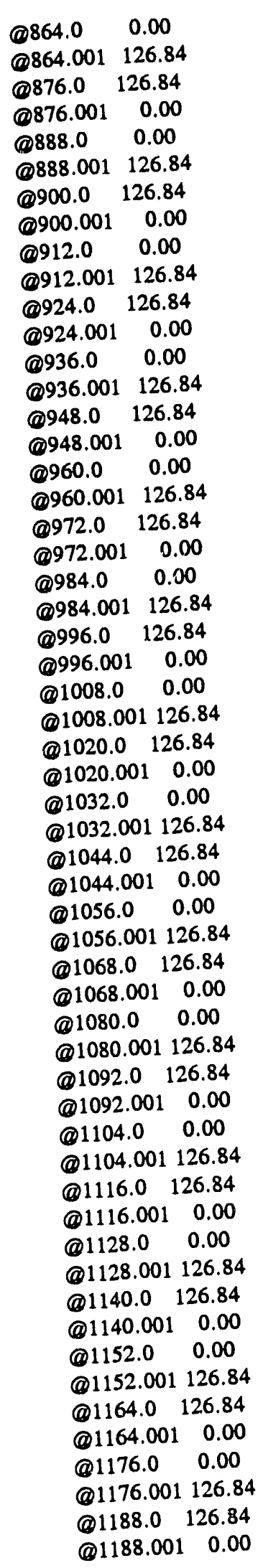




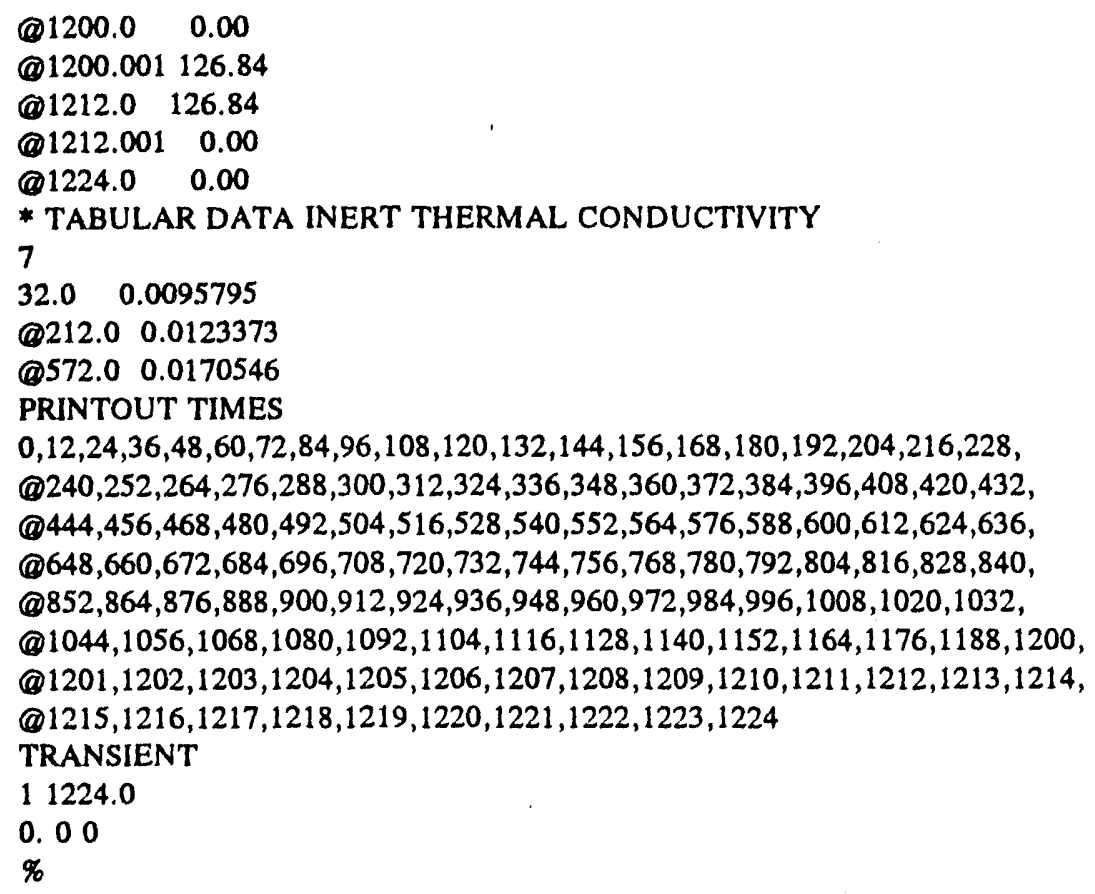



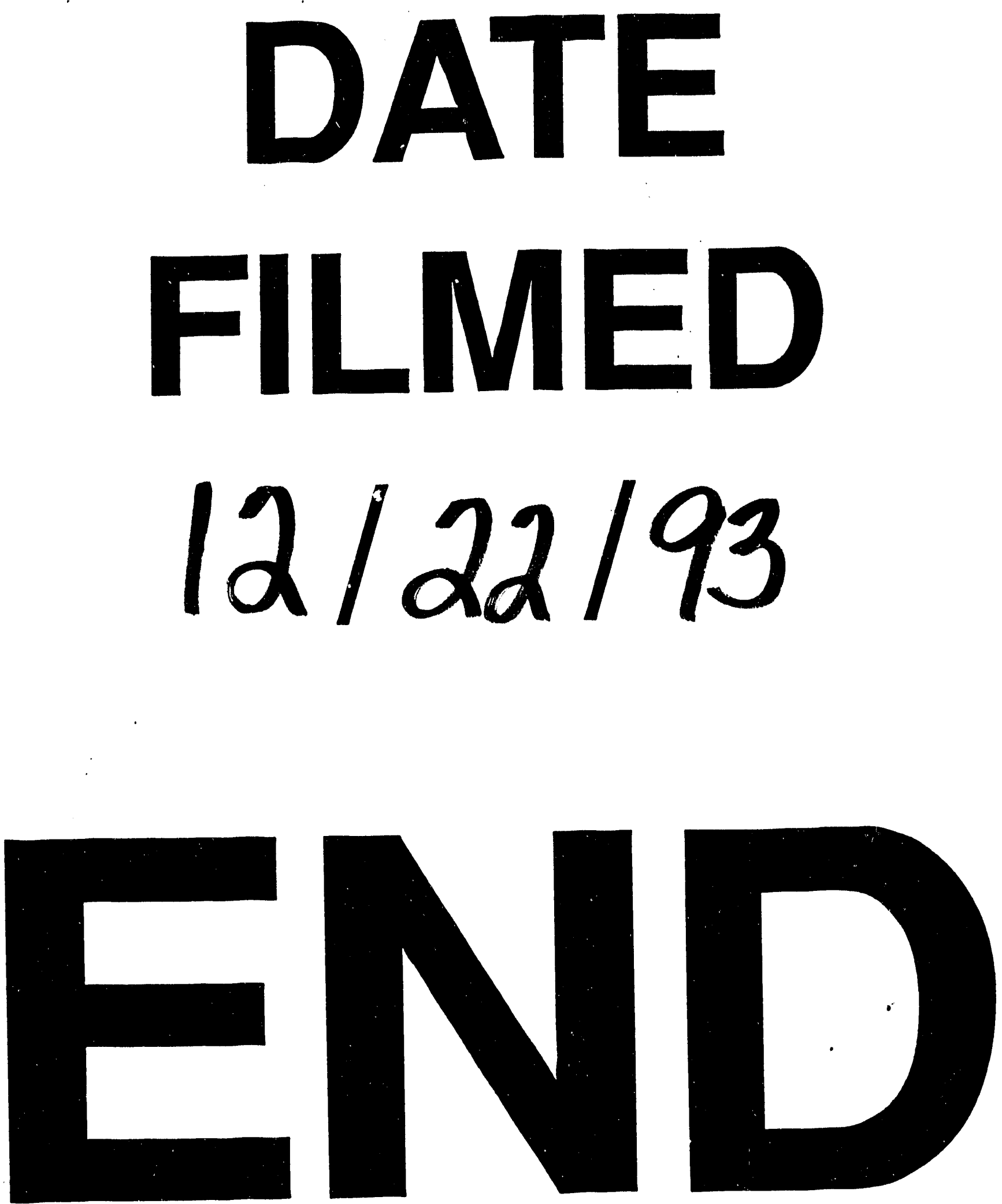
$-$

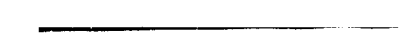

